Journal of Machine Engineering, 2021, Vol. 21, No. 4, 90-105

ISSN 1895-7595 (Print) ISSN 2391-8071 (Online)

Received: 11 October 2021/ Accepted: 25 November 2021/ Published online: 02 December 2021

external cylindrical grinding, MCDM, WASPAS, PIV, decision making

Do Duc TRUNG ${ }^{1 *}$

\title{
THE COMBINATION OF TAGUCHI - ENTROPY - WASPAS - PIV METHODS FOR MULTI-CRITERIA DECISION MAKING WHEN EXTERNAL CYLINDRICAL GRINDING OF 65G STEEL
}

\begin{abstract}
This paper presents a study on the multi-creteria decision making in the external cylindrical grinding process of $65 \mathrm{G}$ steel. An aluminum oxide grinding wheel was used in the experimental process. The experimental matrix was designed according to the Taguchi method with twenty-seven experiments. Five parameters were used to design the experimental matrix including workpiece velocity, feed rate, depth of cut, dressing feed rate, and dressing depth of cut. The surface roughness and Material Removal Rate $(M R R)$ were determined for each experiment. This is the first time that the Weighted Aggregates Sum Product ASsessment (WASPAS) and Proximity Indexed Value $(P I V)$ methods were used to make the multi-criteria decision for grinding process. The weighs of ouput criteria (surface roughness and $M R R$ ) were determined by Entropy method. Both WASPAS and PIV methods determined an experiment that simultaneously ensured the "minimum value" of surface roughness and "maximum value" of $M R R$.
\end{abstract}

\section{Nomenclature}

$R a$ : The arithmetical mean deviation of the assessed profile

$M R R$ : Material removal rate

TOPSIS: Technique for order preference by similarity to ideal solution

VIKOR: Vlsekriterijumska optimizacija i kompromisno resenje in Serbian

MOORA: Multi objective optimization on the basis of ratio analysis

COPRAS: Complex proportional assessment

RIM: Reference ideal method

WASPAS: Weighted aggregates sum product assessment

$P I V$ : Proximity indexed value

$S / N$ : Signal-to-noise ratio

$N N$ : Neural network

$G A$ : Genetic algorithm

$R S M$ : Response surface methodology

$G R A$ : Gray relational analysis

\footnotetext{
${ }^{1}$ Faculty of Mechanical Engineering, Hanoi University of Industry, Vietnam

*E-mail: doductrung@ haui.edu.vn

https://doi.org/10.36897/jme/144260
} 


\section{INTRODUCTION}

The goal of most machining methods is to be able to manufacture machine parts with small surface roughness and high MRR. Because the surface roughness directly affects on the workability of machine parts through the wear resistance, fatigue strength, and chemical corrosion resistance, and $M R R$ is an important parameter to evaluate the machining productivity $[1,2]$.

This problem is even more significant when applying to grinding methods because grinding is known to be the final finishing method for surfaces with small roughness requirement [3]. The productivity when machining by grinding methods is limited because the depth of cut when grinding is often very small [4]. Machining productivity is directly depended on the parameters of the cutting process. But these parameters of the cutting process also have a direct influence on the surface roughness. In addition, surface roughness also depends on many other factors such as parameters of the dressing process, cooling parameters, machining material, conditions of experimental equipment, etc., [5]. Therefore, to ensure the machining process with small surface roughness and high $M R R$, it is required to conduct a case-by-case study. However, within a research process corresponding to a certain experimental system, it is impossible to survey all the above parameters (the parameters that affect on the surface roughness and $M R R$ ). Therefore, in each specific case, only a few parameters can be selected to survey and determine the values of these parameters to ensure small surface roughness and/or large $M R R$. Stemming from this feature, many experimental studies have been carried out to solve this problem.

The Taguchi method was used to design the experimental matrix, and then the $S / N$ analysis method was used in many cases to determine the values of parameters of the machining process to ensure the minimum surface roughness.

When grinding the EN19 steel [6], the authors applied the Taguchi method to design the experimental matrix and applied $\mathrm{S} / \mathrm{N}$ method to analyze the experimental results. They determined that to ensure the minimum value of surface roughness, the workpiece velocity, feed rate, and depth of cut were $410 \mathrm{rev} / \mathrm{min}, 0.18 \mathrm{~mm} / \mathrm{rev}$, and $0.02 \mathrm{~mm}$, respectively. Taguchi and S/N method were also applied to optimize the grinding process of AISI 4140. The results showed that to obtain the minimum value of surface roughnes, the grinding wheel speed was $2640 \mathrm{rev} / \mathrm{min}$, workpiece speed was $710 \mathrm{rev} / \mathrm{min}$, grain size was $46 \mathrm{mesh} / \mathrm{inch}$, depth of cut was $0.015 \mathrm{~mm}$, concentration of the coolant was $5 \%$, and number of passes was 3 [7]. Study on determination of cutting parameters to ensure the minimum value of surface roughness when grinding the AISI D3 steel was also performed according to matrix using Taguchi method. $S / N$ method was also applied to analyze the experimental results [8]. The analyzed results showed that to obtain the smallest surface roughness, the grinding wheel speed was $2000 \mathrm{rev} / \mathrm{min}$, workpiece speed $220 \mathrm{rev} / \mathrm{min}$, feed rate was $3.2 \mathrm{~mm} / \mathrm{rev}$, and depth of cut was $0.005 \mathrm{~mm}$. The grinding process of AISI 1045 was performed according to a matrix using Taguchi method. And then, $S / N$ method was also applied to analyze the experimental results. The results showed that with the grinding wheel speed of $2100 \mathrm{rev} / \mathrm{min}$, workpiece speed of $500 \mathrm{rev} / \mathrm{min}$, grinding grain material of silicon carbide, grain size of 60 , coolant concentration of $3 \%$, and pass number of 4 , the value of surface roughness was smallest [9]. When grinding the 9XC steel, to ensure the minimum of surface roughness, the coarse 
dressing depth of $0.07(\mathrm{~mm})$, the fine dressing depth of $0.02(\mathrm{~mm})$, the number of non-feeding dressing times is 3 [10]. In this study, Taguchi method was also used to design the experimental matrix, and then, $S / N$ method was also used to analyze the experimental results. For EN19 steel, to ensure the minimum value of surface roughness, the dressing depth of cut was 0.02 $\mathrm{mm}$, dressing feed rate was $80 \mathrm{~mm} / \mathrm{min}$, drag angle was $50^{\circ}$, and the number of passes was 4 [11]. Taguchi and $S / N$ methods were also used to design the experimental matrix and analyze the experimental results. The authors performed the grinding process of EN8 steel using four different grinding wheels including $\mathrm{Al}_{2} \mathrm{O}_{3}$ of grades $\mathrm{K}$ and $\mathrm{L}$, and white alumina of grades $\mathrm{J}$ and $\mathrm{K}$. Taguchi and $S / N$ methods were also used to design the experimental matrix and analyze the experimental results. The analyzed results showed that the surface roughness was smallest when using the $\mathrm{Al}_{2} \mathrm{O}_{3}$ of grade $\mathrm{L}$ grinding wheel and with the grinding wheel speed was $1300 \mathrm{rev} / \mathrm{min}$, workpiece speed was $278 \mathrm{rev} / \mathrm{min}$, and depth of cut was $0.03 \mathrm{~mm}$ [12].

Taguchi method was also applied to design an experimental matrix, and then the $S / N$ ratio analysis method was also applied to determine the values of machining parameters to ensure the maximum $M R R$.

When grinding the AISI 31 steel, Taguchi and $\mathrm{S} / \mathrm{N}$ methods were also used to design the experimental matrix and analyze the experimental results. The results showed that to obtain the maximum value of $M R R$, the grinding speed, feed rate, and depth of cut were $1000 \mathrm{rev} / \mathrm{min}, 0.095 \mathrm{~mm} / \mathrm{min}$, and $0.03 \mathrm{~mm}$, respectively [13]. When grinding the AISI 316 steel, to obtain maximum value of $M R R$, the cutting velocity was $560 \mathrm{~m} / \mathrm{min}$, feed rate was $0.13 \mathrm{~mm} / \mathrm{rev}$, and depth of cut was $0.005 \mathrm{~mm}$ [14]. In this study, Taguchi and $S / N$ methods were also used to design the experimental matrix and analyze the experimental results. Taguchi and $S / N$ methods were also used to design the experimental matrix and analyze the experimental results when grinding the $9 \mathrm{CrSi}$ steel [15]. This study showed that to obtain the maximum value of $M R R$, the dressing feed rate was $3 \mathrm{~m} / \mathrm{min}$, coarse dressing depth was $2 \mathrm{~mm}$, coarse dressing times was 1 , fine dressing depth was $1 \mathrm{~mm}$, fine dressing times was 3 , and non-feeding dressing times was 6.

Through some of the above studies, it can be found that the Taguchi method has been successfully applied in many different cylindrical grinding processes. This is also easily explained because the Taguchi method is known as an experimental design method enabling the performance of few experiments with many input parameters, and the input parameters with many levels. Another outstanding advantage of the Taguchi method is that it allows designing an experimental matrix with the input parameters being qualitative ones (such as type of grinding wheel). This is the exclusive advantage of the the matrix design method according to the Taguchi method [16]. However, if only the Taguchi method is applied to design the experimental matrix and then the $S / N$ ratio analysis method is applied, only the values of parameters of the machining process can be determined to ensure only one criterion, such as ensure the integer minimum surface roughness or ensure the integer maximum $M R R$.

In order to overcome this limitation of the Taguchi method, a number of studies were also conducted by combining the matrix design according to the Taguchi method with a certain algorithm. When grinding AISI 316 steel, to simultaneously ensure the minimum value of surface roughness and maximum value of $M R R$, the workpiece velocity was $13 \mathrm{~m} / \mathrm{min}$, feed rate was $17 \mathrm{~mm} / \mathrm{min}$, and depth of cut was $0.01 \mathrm{~mm}$ [17]. To determine these 
velues of cutting parameters, the authors combine the Taguchi method and meta-heuristic algorithm. The Taguchi and GRA were combined when study on the grinding process of $9 \mathrm{CrSi}$ [18]. The results showed that to simultaneously ensure the minimum value of surface roughness and maximum value of $M R R$, the dressing feed rate was $1.4 \mathrm{~mm} / \mathrm{min}$, coarse dressing depth was $0.02 \mathrm{~mm}$, coarse dressing time was 1 , fine dressing depth was $0.005 \mathrm{~mm}$, fine dressing times was 1 , and non-feeding dressing was 5. The authors combined the Taguchi, RSM, and GA method when study on the grinding process of 6061-T4 aluminum alloy [19]. The results showed that to simultaneously ensure the minimum values of surface roughness and vibirations, the values of infeed, longitudinal feed, and work speed were $0.04 \mathrm{~mm} /$ cycle, $70 \mathrm{~mm} / \mathrm{s}$, and $80 \mathrm{rev} / \mathrm{min}$, respectively.

In addition to combining the Taguchi method with a number of algorithms as presented above, to simultaneously ensure the multiple criteria of a machining process or of a certain operation, a concept that is known as "multi-criteria decision making - MCDM" is created. In order to realize multi-criteria decision making, the combination of the Taguchi method and mathematical methods has been carried out in many studies under many different fields. Some commonly used techniques, such as: TOPSIS [20], VIKOR [21], MOORA [22], COPRAS [23], RIM [24], WASPAS [25], PIV [26], etc.

However, when using methods such as TOPSIS, VIKOR, MOORA, COPRAS, RIM to rank the alternatives, it is very easy to occur the reversal to solutions. That is, if we add or subtract a certain solution, the order of the previously ranked solutions will not be maintained, sometimes even creating an opposite ranking compared to the original ranking [26]. The PIV method is known as a multi-criteria decision making method which enables to minimize the possibility of reversibility to solutions [26]. This method has been successfully applied in $M C D M$ when ranking and selecting E-learning sites [27], for the selection of materials for manufacturing some parts of automobiles [28], for the selection of elements for logistics activities of the EU countries [29], for the selection of additives in a production process [30], etc. The WASPAS method has also been successful in MCDM in some studies, such as: in recovering used mobile phones [31], in human resource management to ensure the continuous development and satisfaction of employees [32], in selection of materials of a production process [33], in multi-criteria decision making when turning aluminum [34], in development of Klaipeda sea port [35], etc. However, until now, there have been no studies that apply such two methods (WASPAS and $P I V$ ) for $M C D M$ in external cylindrical grinding.

It is also important to note that when $M C D M$, it is required to determine the weight of each criterion. However, if the weighting of the criteria is done according to the subjective opinion of the decision maker, it is a lack of necessary reliability. The weighting of each criterion which is done by expert opinions also depends a lot on the knowledge of the experts, and sometimes also greatly influenced by the design of questionnaires. Determining weights for criteria by Entropy method which is a well-known method, has been applied in many cases. However, unfortunately, to date, there have been no studies that apply the Entropy method to determine the weight of criteria in the external cylindrical grinding process.

To machine parts with high requirements for hardness and wear resistance such as those in the cement, thermal power, and sugar industries, 65G steel is one of the first selected materials. When machining surfaces with requirements for high precision of these parts, the cylindrical grinding method is often chosen as the final machining method. Several studies 
on grinding this steel (or equivalent steels) have been published, such as the study on changes in hardness after grinding [36], the study on the cutting force when grinding [37], the study on the effect of cutting parameters on surface roughness when face grinding [38]. However, a surprising thing has been discovered that up to now, there has been no published research on determining the value of technological parameters to simultaneously ensure the minimum surface roughness and the maximum $M R R$ when circular grinding this type of steel.

From the above analysis and comments, it is shown that: Firstly, the Taguchi method shows many advantages in designing an experimental matrix, but the combination of Taguchi method and the two methods (WASPAS and PIV) has not been implemented in any studies on grinding in general as well as the external cylindrical grinding method in particular; Secondly, the application of the Entropy method to determine the weights of criteria has not been applied to the external cylindrical grinding method; Thirdly, No published research has been found on the simultaneous survey of two parameters (surface roughness and $M R R$ ) when cylindrical grinding $65 \mathrm{G}$ steel. These gaps will be covered in this study. Specifically, the experiments of cylindrical grinding $65 \mathrm{G}$ steel will be carried out according to the designing matrix by Taguchi method, Entropy method will be applied to determine the weights of surface roughness and MRR, WASPAS and PIV methods will be applied for multi-criteria decision making.

\section{DETERMINATION OF THE WEIGHT USING ENTROPY METHOD}

Determining the weights of criteria using Entropy method is done according to the following steps [39].

Step 1. Determine the normalized values for criteria

$$
p_{\mathrm{ij}}=\frac{x_{\mathrm{ij}}}{m+\sum_{i=1}^{m} x_{\mathrm{ij}}^{2}}
$$

where: $x_{i j}$ is the value of criterion $j$ corresponding to option $i ; m$ is the number of options.

Step 2. Calculate the value of the Entropy measure for each criterion.

$$
e_{\mathrm{j}}=-\sum_{i=1}^{m}\left[p_{\mathrm{ij}} \times \ln \left(\mathrm{p}_{\mathrm{ij}}\right)\right]-\left(1-\sum_{i=1}^{m} p_{\mathrm{ij}}\right) \times \ln \left(1-\sum_{i=1}^{m} p_{\mathrm{ij}}\right)
$$

Step 3. Calculate the weight for each criterion.

$$
\mathrm{w}_{\mathrm{j}}=\frac{1-\mathrm{ej}}{\sum_{j=1}^{n}(1-\mathrm{ej})}
$$

\section{MULTI-CRITERIA DECISION MAKING METHODS}

\subsection{WASPAS METHOD}

The WASPAS method was first recommended in 2012 [25], the implementation steps of this method are as follows:

Step 1. Establish the initial decision-making matrix $(X)$ as shown in formula (4) 


$$
\begin{aligned}
& \begin{array}{lllll}
C_{1} & C_{2} & \cdots & C_{n}
\end{array} \\
& X=\begin{array}{l}
S_{1} \\
S_{2} \\
\cdots \\
S_{m}
\end{array}\left[\begin{array}{cccc}
x_{11} & x_{12} & \cdots & x_{1 n} \\
x_{21} & x_{22} & \cdots & x_{2 n} \\
\cdots & \cdots & \cdots & \cdots \\
x_{m 1} & x_{m 2} & \cdots & x_{m n}
\end{array}\right]
\end{aligned}
$$

where: $m$ is the number of options $\left(S_{1}, S_{2}, \ldots, S_{m}\right), n$ is the number of criteria $\left(C_{1}, C_{2}, \ldots, C_{n}\right)$. Step 2. Determine the normalized matrix using the following equations.

$$
\begin{aligned}
& n_{\mathrm{ij}}=\frac{x_{\mathrm{ij}}}{\max x_{i j}} \text { for } C_{1}, C_{2}, \ldots, C_{n} \in B \\
& n_{\mathrm{ij}}=\frac{\min x_{\mathrm{ij}}}{x_{i j}} \text { for } C_{1}, C_{2}, \ldots, C_{n} \in C
\end{aligned}
$$

Of which $B$ represents the benefit criteria, $C$ represents the cost criteria.

Step 3. Develop a weight matrix by multiplying the initial matrix by the weight of the criteria, of which $w_{j}$ is the weight of the criterion $j$.

$$
\begin{gathered}
v_{n}=\left[v_{\mathrm{ij}}\right]_{m \times n} \\
v_{i j}=w_{j} \times n_{i j}, \quad i=1,2, \ldots, m \quad j=1,2, \ldots, n
\end{gathered}
$$

Step 4. Add up all values of the criteria in each option (sum by rows).

$$
\begin{aligned}
& Q_{i}=\left[q_{\mathrm{ij}}\right]_{1 \times m} \\
& q_{\mathrm{ij}}=\sum_{j=1}^{n} v_{\mathrm{ij}}
\end{aligned}
$$

Step 5. Determine the weighted product model according to the following formulas.

$$
\begin{gathered}
P_{i}=\left[p_{\mathrm{ij}}\right]_{1 \times m} \\
p_{\mathrm{ij}}=\prod_{j=1}^{n}\left(v_{\mathrm{ij}}\right)^{\mathrm{w}_{j}}
\end{gathered}
$$

Step 6. Determine the relative values of the options $A_{i}$ according to the formulas.

$$
\begin{gathered}
A_{i}=\left[a_{\mathrm{ij}}\right]_{1 \times m} \\
A_{\mathrm{i}}=\lambda \times Q_{i}+(1-\lambda) \times P_{i}
\end{gathered}
$$

Of which the coefficient $\lambda$ can choose one of the following values: $0 ; 0.1 ; 0.2 ; \ldots ; 1.0$ Step 7. Rank the options according to the principle, the one with the maximum $A_{i}$ is the best, whereas the worst one obtains the minimum $A_{i}$.

\subsection{PIV METHOD}

$P I V$ is a method for multi-criteria decision making, first introduced in 2018 [26]. The steps to implement multi-criteria decision making according to this method are as follows.

Step 1. Describe solutions $S_{i}$ (with $j=1,2, \ldots, m$ ) and criteria $C_{i}$ (with $j=1,2, \ldots, n$ ). 
Step 2. Develop a decision matrix $X$ by arranging the solutions by rows and the criteria by columns as shown in the formula (4).

Step 3. Determine the normalized decision matrix using the formula (15).

$$
R_{j}=\frac{x_{j}}{\sqrt{\sum_{i=1}^{m} x_{j}^{2}}}
$$

Of which $x_{i}$ is the actual decision value of the option $i$.

Step 4. Determine the weighted normalized decision matrix according to the formula (16)

$$
v_{j}=\mathrm{w}_{\mathrm{j}} \times R_{j}
$$

Of which $w_{j}$ is the weight of the criterion $j$.

Step 5. Evaluate the weighted proximity index according to the formula (17).

$$
u_{i}=\left\{\begin{array}{cc}
v i_{\max } & \text { for beneficial attributes } \\
v_{i}-v_{\min } & \text { for cos } t \text { attributes }
\end{array}\right.
$$

Step 6. Determine the overall proximity value according to the formula (18).

$$
d_{i}=\sum_{j=1}^{n} u_{i}
$$

Step 7. Rank the solutions according to the principle that the solution with the minimum $d_{i}$ is the best.

\section{GRINDING PROCESS EXPERIMENT}

The $65 \mathrm{G}$ steel samples used in this study have been heat treated to a hardness of $62 \mathrm{HRC}$. The workpiece has diameter and length of $30 \mathrm{~mm}$ and $320 \mathrm{~mm}$, respectively, but only performs the grinding process on the 250 length of the workpiece, the rest is for mounting parts (position for clamping buckles).

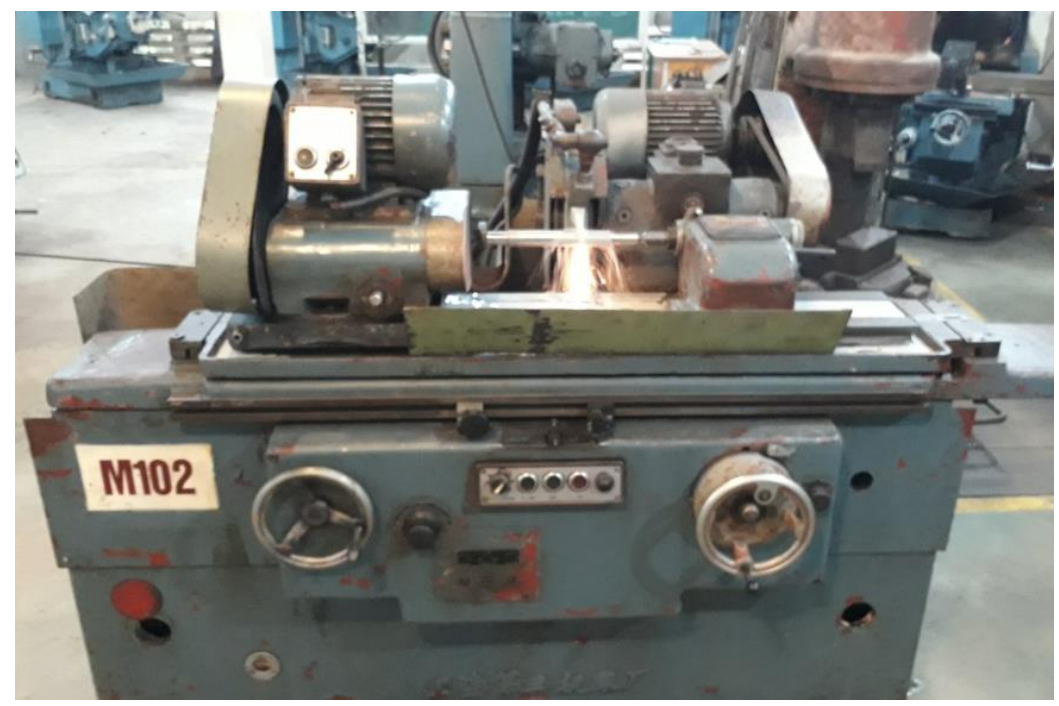

Fig. 1. Cylindrical grinder 
The experiments were carried out on a traditional external cylindrical grinding machine (GU32x100S of Palmary Brand, Taiwan) as described in Fig. 1. The grinding wheel that was produced by Vietnam's Hai Duong grinding wheel company was used in this study. This grinding wheel is aluminum oxide wheel $(C n)$, grain size 80 , ceramic binder $(G)$, average hardness of $1\left(T B_{l}\right)$, cylindrical wheel type $(V)$, the maximum allowable velocity recommended by the wheel manufacturer of $35 \mathrm{~m} / \mathrm{s}$. The full symbol of the grinding wheel is

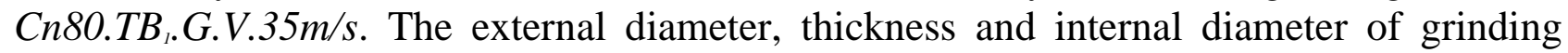
wheels are $280 \mathrm{~mm}, 40 \mathrm{~mm}$ and $115 \mathrm{~mm}$, respectively. Dressing by a multi-point diamond dresser with the symbol 3908-0088C (Russian Federation).

The experimental matrix was designed according to the Taguchi method with a total twenty-seven experiments. Parameters including workpiece speed, feed rate, depth of cut, dressing feed rate, and dressing depth were selected as the input ones. The reason these parameters are selected is because the adjustment to such parameters' values is done more quickly by the machine operator than the adjustment to other parameters (type of grinding wheels, type of coolants, parameters of the grinding machine, etc). Each input parameter has selected three levels of values as shown in Table 1, the experimental matrix is presented in Table 2.

Table 1. Value of input parameters at levels

\begin{tabular}{|l|c|c|c|c|c|}
\hline \multirow{2}{*}{\multicolumn{1}{|c|}{ Parameter }} & \multirow{2}{*}{ Symbol } & \multirow{2}{*}{ Unit } & \multicolumn{3}{c|}{ Value at level } \\
\cline { 4 - 6 } & & & 1 & 2 & 3 \\
\hline Workpiece speed & $n$ & rev/min & 400 & 600 & 800 \\
\hline Feed rate & $f_{w}$ & $\mathrm{~mm} / \mathrm{rev}$ & 0.05 & 0.075 & 0.09 \\
\hline Depth of cut & $a_{r}$ & $\mathrm{~mm}$ & 0.01 & 0.015 & 0.02 \\
\hline Dressing feed rate & $f_{d}$ & $\mathrm{~mm} / \mathrm{min}$ & 100 & 150 & 200 \\
\hline Dressing depth & $a_{d}$ & $\mathrm{~mm}$ & 0.005 & 0.01 & 0.015 \\
\hline
\end{tabular}

Table 2. Experimental matrix and responses

\begin{tabular}{|c|c|c|c|c|c|c|c|c|c|c|c|c|}
\hline \multirow{2}{*}{ Trial } & \multicolumn{5}{|c|}{$\begin{array}{l}\text { Code value of input } \\
\text { parameters }\end{array}$} & \multicolumn{5}{|c|}{ Actual value of input parameters } & \multicolumn{2}{|c|}{ Responses } \\
\hline & $n$ & $f_{w}$ & $a_{r}$ & $f_{d}$ & $a_{d}$ & $\begin{array}{c}n \\
(\mathrm{rev} / \mathrm{min})\end{array}$ & $\begin{array}{c}f_{w} \\
(\mathrm{~mm} / \mathrm{rev})\end{array}$ & $\begin{array}{c}a_{r} \\
(m m)\end{array}$ & $\begin{array}{c}f_{d} \\
(\mathrm{~mm} / \mathrm{min})\end{array}$ & $\begin{array}{c}a_{d} \\
(m m)\end{array}$ & $\begin{array}{c}R_{a} \\
(/ m)\end{array}$ & $\begin{array}{c}M R R \\
\left(\mathrm{~mm}^{3} / \mathrm{min}\right)\end{array}$ \\
\hline 1 & 1 & 1 & 1 & 1 & 1 & 400 & 0.05 & 0.01 & 100 & 0.005 & 0.295 & 18.843 \\
\hline 2 & 1 & 1 & 1 & 1 & 2 & 400 & 0.05 & 0.01 & 100 & 0.01 & 0.332 & 18.843 \\
\hline 3 & 1 & 1 & 1 & 1 & 3 & 400 & 0.05 & 0.01 & 100 & 0.015 & 0.370 & 18.843 \\
\hline 4 & 1 & 2 & 2 & 2 & 1 & 400 & 0.075 & 0.015 & 150 & 0.005 & 0.399 & 42.39 \\
\hline 5 & 1 & 2 & 2 & 2 & 2 & 400 & 0.075 & 0.015 & 150 & 0.01 & 0.436 & 42.39 \\
\hline 6 & 1 & 2 & 2 & 2 & 3 & 400 & 0.075 & 0.015 & 150 & 0.015 & 0.474 & 42.39 \\
\hline 7 & 1 & 3 & 3 & 3 & 1 & 400 & 0.09 & 0.02 & 200 & 0.005 & 0.489 & 67.813 \\
\hline 8 & 1 & 3 & 3 & 3 & 2 & 400 & 0.09 & 0.02 & 200 & 0.01 & 0.527 & 67.813 \\
\hline 9 & 1 & 3 & 3 & 3 & 3 & 400 & 0.09 & 0.02 & 200 & 0.015 & 0.564 & 67.813 \\
\hline 10 & 2 & 1 & 2 & 3 & 1 & 600 & 0.05 & 0.015 & 200 & 0.005 & 0.425 & 42.39 \\
\hline 11 & 2 & 1 & 2 & 3 & 2 & 600 & 0.05 & 0.015 & 200 & 0.01 & 0.460 & 42.39 \\
\hline 12 & 2 & 1 & 2 & 3 & 3 & 600 & 0.05 & 0.015 & 200 & 0.015 & 0.495 & 42.39 \\
\hline 13 & 2 & 2 & 3 & 1 & 1 & 600 & 0.075 & 0.02 & 100 & 0.005 & 0.312 & 84.766 \\
\hline 14 & 2 & 2 & 3 & 1 & 2 & 600 & 0.075 & 0.02 & 100 & 0.01 & 0.347 & 84.766 \\
\hline 15 & 2 & 2 & 3 & 1 & 3 & 600 & 0.075 & 0.02 & 100 & 0.015 & 0.382 & 84.766 \\
\hline 16 & 2 & 3 & 1 & 2 & 1 & 600 & 0.09 & 0.01 & 150 & 0.005 & 0.408 & 50.877 \\
\hline
\end{tabular}




\begin{tabular}{|c|c|c|c|c|c|c|c|c|c|c|c|c|}
\hline 17 & 2 & 3 & 1 & 2 & 2 & 600 & 0.09 & 0.01 & 150 & 0.01 & 0.443 & 50.877 \\
\hline 18 & 2 & 3 & 1 & 2 & 3 & 600 & 0.09 & 0.01 & 150 & 0.015 & 0.478 & 50.877 \\
\hline 19 & 3 & 1 & 3 & 2 & 1 & 800 & 0.05 & 0.02 & 150 & 0.005 & 0.417 & 75.348 \\
\hline 20 & 3 & 1 & 3 & 2 & 2 & 800 & 0.05 & 0.02 & 150 & 0.01 & 0.457 & 75.348 \\
\hline 21 & 3 & 1 & 3 & 2 & 3 & 800 & 0.05 & 0.02 & 150 & 0.015 & 0.497 & 75.348 \\
\hline 22 & 3 & 2 & 1 & 3 & 1 & 800 & 0.075 & 0.01 & 200 & 0.005 & 0.542 & 56.53 \\
\hline 23 & 3 & 2 & 1 & 3 & 2 & 800 & 0.075 & 0.01 & 200 & 0.01 & 0.582 & 56.53 \\
\hline 24 & 3 & 2 & 1 & 3 & 3 & 800 & 0.075 & 0.01 & 200 & 0.015 & 0.622 & 56.53 \\
\hline 25 & 3 & 3 & 2 & 1 & 1 & 800 & 0.09 & 0.015 & 100 & 0.005 & 0.398 & 101.737 \\
\hline 26 & 3 & 3 & 2 & 1 & 2 & 800 & 0.09 & 0.015 & 100 & 0.01 & 0.438 & 101.737 \\
\hline 27 & 3 & 3 & 2 & 1 & 3 & 800 & 0.09 & 0.015 & 100 & 0.015 & 0.478 & 101.737 \\
\hline
\end{tabular}

Each experimental sample was measured for its surface roughness $(R a)$ using a SJ-201 meter of Mitutoyo (Japan). The standard length of the measurement has been set to $0.8 \mathrm{~mm}$. Each experimental sample is measured at least three times, the measurement direction is parallel to the sample centerline (perpendicular to the cutting velocity vector). Surface roughness at each experiment was calculated as the average of successive measurements.

$M R R$ is calculated as the amount of material takeoff in one minute. This quantity is calculated by subtracting the volume of the workpiece after grinding from the volume of the workpiece before grinding and then dividing it by the grinding time, of which the grinding time is calculated by the grinding length divided by the displacement velocity of the grinding wheel head (the feed rate).

The experiments were carried out under the following conditions: the speed of grinding wheel spindle $1750 \mathrm{rev} / \mathrm{min}$; using N-600 industrial oil (made in Vietnam) with a concentration of $12 \%$, flow rate 16 liters/min. These values have been selected according to the recommenddations of the coolant factory and the grinding wheel manufacturer.

\section{RESULTS AND DISCUSSION}

\subsection{ANALYZING THE EXPERIMENTAL RESULTS}

With the selected significance level of 0.05 [40], to investigate the influence of the input parameters on the surface roughness, the analysis of variance (ANOVA) was performed, the analyzed results are presented in Table 3. From the data in Table 3 showed that the probability $P$-value of the workpiece speed, dressing feed rate, and dressing depth of cut are all much smaller than the significance level. Thus, we conclude that these four parameters all significantly affect on the surface roughness. The dressing feed rate and dressing depth of cut are two parameters that have a great influence on the topography of the grinding wheel, thereby greatly influencing on the shape, size, and number of scratches of the grinding grains left on the workpiec surface, so they greatly affect on the surface roughness [41]. The change of the workpiece speed and the feed rate will change the contact time between the grinding wheel surface and the workpiece surface, thereby also changing the number of grinding grain scratches left on the workpiece surface as well as the changing the amount of heat transferred to the workpiece surface, thereby changing the surface roughness [42]. 
Table 3. The ANOVA results

\begin{tabular}{|l|c|c|c|c|c|c|c|c|}
\hline Factors & Coefficients & $\begin{array}{c}\text { Standard } \\
\text { Error }\end{array}$ & $\mathrm{t}$ Stat & P-value & $\begin{array}{c}\text { Lower } \\
95 \%\end{array}$ & $\begin{array}{c}\text { Upper } \\
95 \%\end{array}$ & $\begin{array}{c}\text { Lower } \\
95.0 \%\end{array}$ & $\begin{array}{c}\text { Upper } \\
95.0 \%\end{array}$ \\
\hline Intercept & -0.0275 & 0.0386 & -0.7118 & 0.4844 & -0.1077 & 0.0528 & -0.1077 & 0.0528 \\
\hline$n$ & 0.0002 & 0.0000 & 5.2199 & 0.0000 & 0.0001 & 0.0002 & 0.0001 & 0.0002 \\
\hline$f_{w}$ & 1.3426 & 0.2870 & 4.6774 & 0.0001 & 0.7457 & 1.9396 & 0.7457 & 1.9396 \\
\hline$a_{r}$ & -0.8889 & 1.1601 & -0.7662 & 0.4521 & -3.3014 & 1.5237 & -3.3014 & 1.5237 \\
\hline$f_{d}$ & 0.0015 & 0.0001 & 12.9683 & 0.0000 & 0.0013 & 0.0017 & 0.0013 & 0.0017 \\
\hline$a_{d}$ & 7.5000 & 1.1601 & 6.4650 & 0.0000 & 5.0875 & 9.9125 & 5.0875 & 9.9125 \\
\hline
\end{tabular}

The probability $P$-value of the depth of cut equals to 0.4521 , this value is much larger than the significance level, so this parameter does not significantly affect on the surface roughness. When using aluminum oxide grinding wheel, cutting heat is transferred to the workpiece surface a large amount (about 60 to $90 \%$ of the total heat that is generated during grinding). This amount of heat can cause the metal layer at the machined surface to reach a molten state [43]. And so, the change in the depth of cut may having a negligible influence on the tangential cutting force component with the machining surface. Therefore, depth of cut has no significant effect on the surface roughness.

The data in Table 3 also showed that when increasing the value of the workpiece speed, feed rate, dressing feed rate, and dressing depth of cut, the surface roughness will increase (because the coefficients correspond to these parameters are the positive values). In contrast, when increasing the depth of cut, the surface roughness decreases (because the coefficient corresponding to this parameter is negative value). From there, it is shown that, in order to reduce surface roughness, it is necessary to reduce the workpiece speed, feed rate, dressing feed rate, and dressing depth of cut, and to increase the cutting depth. However, it is also easy to see that reducing the cutting speed and feed rate causes the $M R R$ to decrease. From that, it can be seen that it is difficult to determine the value of the input parameters to simultaneously ensure the minimum value of surface roughness and the maximum value of $M R R$.

On the other hand, observing the data in Table 2 shows that: the experiment No. 1 has the minimum surface roughness, but also in this experiment, the $M R R$ is also the minimum; Experiments No. 25, No. 26 and No. 27 have the maximum $M R R$, but also in such three experiments, the surface roughness is not the minimum. From there, it can be seen that if we only observe the data in Table 2, we will also fail in selecting the experiment (out of a total of twenty-seven experiments) to simultaneously ensure the minimum surface roughness and the maximum MRR. The fact also confirms that there is no experiment out of the total of twenty-seven experiments in Table 2 that guarantees absolute minimum surface roughness and absolute maximum $M R R$. Therefore, we can only determine the experiment where the surface roughness is considered to be the "minimum" and the MRR is considered the "maximum". And of course, to do this, it is required to perform MCDM when considering the weight of each criterion.

\subsection{MULTI-CRITERIA DECISION MAKING USING THE WASPAS METHOD}

Applying the formulas (1), (2) and (3) to determine the weighs for the criteria as follows: $w_{R a}=0.1598 ; w_{M R R}=0.8402$. 
Applying the formula (4) to form the initial decision making matrix $(X)$. This matrix is the last two columns in Table 2. Applying formulas (5), (6) to calculate $n_{i}$ value. Applying formulas (7), (8) to calculate $v_{i}$ value. The results are presented in Table 4.

Table 4. Values of $n_{i}$ and $v_{i}$ in WASPAS

\begin{tabular}{|c|c|c|c|c|}
\hline \multirow{2}{*}{ Solutions } & \multicolumn{2}{|c|}{$n_{i}$} & \multicolumn{2}{c|}{$v_{i}$} \\
\cline { 2 - 5 } & $R a$ & $M R R$ & $R a$ & $M R R$ \\
\hline$S_{I}$ & 1.0000 & 0.1852 & 0.1598 & 0.1556 \\
\hline$S_{2}$ & 0.8886 & 0.1852 & 0.1420 & 0.1556 \\
\hline$S_{3}$ & 0.7973 & 0.1852 & 0.1274 & 0.1556 \\
\hline$S_{4}$ & 0.7393 & 0.4167 & 0.1181 & 0.3501 \\
\hline$S_{5}$ & 0.6766 & 0.4167 & 0.1081 & 0.3501 \\
\hline$S_{6}$ & 0.6224 & 0.4167 & 0.0995 & 0.3501 \\
\hline$S_{7}$ & 0.6033 & 0.6666 & 0.0964 & 0.5600 \\
\hline$S_{8}$ & 0.5598 & 0.6666 & 0.0895 & 0.5600 \\
\hline$S_{9}$ & 0.5230 & 0.6666 & 0.0836 & 0.5600 \\
\hline$S_{I 0}$ & 0.6941 & 0.4167 & 0.1109 & 0.3501 \\
\hline$S_{I I}$ & 0.6413 & 0.4167 & 0.1025 & 0.3501 \\
\hline$S_{I 2}$ & 0.5960 & 0.4167 & 0.0952 & 0.3501 \\
\hline$S_{13}$ & 0.9455 & 0.8332 & 0.1511 & 0.7000 \\
\hline$S_{I 4}$ & 0.8501 & 0.8332 & 0.1359 & 0.7000 \\
\hline$S_{I 5}$ & 0.7723 & 0.8332 & 0.1234 & 0.7000 \\
\hline$S_{16}$ & 0.7230 & 0.5001 & 0.1155 & 0.4202 \\
\hline$S_{I 7}$ & 0.6659 & 0.5001 & 0.1064 & 0.4202 \\
\hline$S_{I 8}$ & 0.6172 & 0.5001 & 0.0986 & 0.4202 \\
\hline$S_{I 9}$ & 0.7074 & 0.7406 & 0.1130 & 0.6223 \\
\hline$S_{20}$ & 0.6455 & 0.7406 & 0.1032 & 0.6223 \\
\hline$S_{2 l}$ & 0.5936 & 0.7406 & 0.0949 & 0.6223 \\
\hline$S_{22}$ & 0.5443 & 0.5556 & 0.0870 & 0.4669 \\
\hline$S_{23}$ & 0.5069 & 0.5556 & 0.0810 & 0.4669 \\
\hline$S_{24}$ & 0.4743 & 0.5556 & 0.0758 & 0.4669 \\
\hline$S_{25}$ & 0.7412 & 1.0000 & 0.1184 & 0.8402 \\
\hline$S_{26}$ & 0.6735 & 1.0000 & 0.1076 & 0.8402 \\
\hline$S_{27}$ & 0.6172 & 1.0000 & 0.0986 & 0.8402 \\
\hline & & & & \\
\hline
\end{tabular}

Applying formulas (9), (10) we can obtain the value of $Q_{i}$. Applying formulas (11), (12) we can obtain the value of $P_{i}$. Applying formulas (13), (14) we can obtain the value of $A_{i}$. These values were included in Table 5. The ranking of options according to the values of $A_{i}$ were performed and included in Table 5.

Table 5. Several parameters in WASPAS

\begin{tabular}{|c|c|c|c|c|}
\hline Solutions & $Q_{i}$ & $P_{i}$ & $A_{i}$ & Rank \\
\hline$S_{1}$ & 0.3154 & 0.1577 & 0.2366 & 25 \\
\hline$S_{2}$ & 0.2976 & 0.1486 & 0.2231 & 26 \\
\hline$S_{3}$ & 0.2830 & 0.1408 & 0.2119 & 27 \\
\hline$S_{4}$ & 0.4682 & 0.2034 & 0.3358 & 19 \\
\hline$S_{5}$ & 0.4582 & 0.1946 & 0.3264 & 21 \\
\hline$S_{6}$ & 0.4495 & 0.1866 & 0.3181 & 23 \\
\hline$S_{7}$ & 0.6564 & 0.2324 & 0.4444 & 10 \\
\hline$S_{8}$ & 0.6495 & 0.2238 & 0.4367 & 11 \\
\hline
\end{tabular}




\begin{tabular}{|c|c|c|c|c|}
\hline$S_{9}$ & 0.6436 & 0.2164 & 0.4300 & 12 \\
\hline$S_{10}$ & 0.4610 & 0.1971 & 0.3290 & 20 \\
\hline$S_{11}$ & 0.4526 & 0.1894 & 0.3210 & 22 \\
\hline$S_{I 2}$ & 0.4453 & 0.1826 & 0.3140 & 24 \\
\hline$S_{13}$ & 0.8511 & 0.3252 & 0.5882 & 4 \\
\hline$S_{14}$ & 0.8359 & 0.3084 & 0.5721 & 5 \\
\hline$S_{15}$ & 0.8234 & 0.2939 & 0.5587 & 6 \\
\hline$S_{16}$ & 0.5357 & 0.2203 & 0.3780 & 13 \\
\hline$S_{17}$ & 0.5266 & 0.2115 & 0.3690 & 16 \\
\hline$S_{18}$ & 0.5188 & 0.2036 & 0.3612 & 18 \\
\hline$S_{19}$ & 0.7353 & 0.2652 & 0.5003 & 7 \\
\hline$S_{20}$ & 0.7254 & 0.2534 & 0.4894 & 8 \\
\hline$S_{21}$ & 0.7171 & 0.2429 & 0.4800 & 9 \\
\hline$S_{22}$ & 0.5538 & 0.2015 & 0.3777 & 14 \\
\hline$S_{23}$ & 0.5479 & 0.1945 & 0.3712 & 15 \\
\hline$S_{24}$ & 0.5426 & 0.1881 & 0.3654 & 17 \\
\hline$S_{25}$ & 0.9586 & 0.3155 & 0.6371 & 1 \\
\hline$S_{26}$ & 0.9478 & 0.3007 & 0.6243 & 2 \\
\hline$S_{27}$ & 0.9388 & 0.2879 & 0.6133 & 3 \\
\hline
\end{tabular}

\subsection{MULTI-CRITERIA DECISION MAKING USING THE PIV METHOD}

The main decision making matrix is the matrix produced by the last two columns of Table 2. Applying the formula (15) to calculate $R_{i}$ values, apply the formula (16) to calculate $v_{i}$ values, as shown in Table 6 .

Table 6. Value of $R_{i}$ and $v_{i}$ in $P I V$

\begin{tabular}{|c|c|c|c|c|}
\hline \multirow{2}{*}{ Solutions } & \multicolumn{2}{|c|}{$R_{i}$} & \multicolumn{2}{c|}{$v i$} \\
\cline { 2 - 5 } & $R a$ & $M R R$ & $R a$ & $M R R$ \\
\hline$S_{1}$ & 0.0369 & 1.0580 & 0.0059 & 0.8889 \\
\hline$S_{2}$ & 0.0467 & 1.0580 & 0.0075 & 0.8889 \\
\hline$S_{3}$ & 0.0580 & 1.0580 & 0.0093 & 0.8889 \\
\hline$S_{4}$ & 0.0675 & 5.3542 & 0.0108 & 4.4986 \\
\hline$S_{5}$ & 0.0806 & 5.3542 & 0.0129 & 4.4986 \\
\hline$S_{6}$ & 0.0953 & 5.3542 & 0.0152 & 4.4986 \\
\hline$S_{7}$ & 0.1014 & 13.7022 & 0.0162 & 11.5126 \\
\hline$S_{8}$ & 0.1178 & 13.7022 & 0.0188 & 11.5126 \\
\hline$S_{9}$ & 0.1349 & 13.7022 & 0.0216 & 11.5126 \\
\hline$S_{10}$ & 0.0766 & 5.3542 & 0.0122 & 4.4986 \\
\hline$S_{11}$ & 0.0897 & 5.3542 & 0.0143 & 4.4986 \\
\hline$S_{12}$ & 0.1039 & 5.3542 & 0.0166 & 4.4986 \\
\hline$S_{13}$ & 0.0413 & 21.4096 & 0.0066 & 17.9884 \\
\hline$S_{14}$ & 0.0511 & 21.4096 & 0.0082 & 17.9884 \\
\hline$S_{15}$ & 0.0619 & 21.4096 & 0.0099 & 17.9884 \\
\hline$S_{16}$ & 0.0706 & 7.7127 & 0.0113 & 6.4802 \\
\hline$S_{17}$ & 0.0832 & 7.7127 & 0.0133 & 6.4802 \\
\hline$S_{18}$ & 0.0969 & 7.7127 & 0.0155 & 6.4802 \\
\hline$S_{19}$ & 0.0737 & 16.9165 & 0.0118 & 14.2132 \\
\hline$S_{20}$ & 0.0885 & 16.9165 & 0.0141 & 14.2132 \\
\hline$S_{21}$ & 0.1047 & 16.9165 & 0.0167 & 14.2132 \\
\hline$S_{22}$ & 0.1245 & 9.5219 & 0.0199 & 8.0003 \\
\hline$S_{23}$ & 0.1436 & 9.5219 & 0.0229 & 8.0003 \\
\hline & & & & \\
\hline
\end{tabular}




\begin{tabular}{|c|c|c|c|c|}
\hline$S_{24}$ & 0.1640 & 9.5219 & 0.0262 & 8.0003 \\
\hline$S_{25}$ & 0.0672 & 30.8407 & 0.0107 & 25.9123 \\
\hline$S_{26}$ & 0.0813 & 30.8407 & 0.0130 & 25.9123 \\
\hline$S_{27}$ & 0.0969 & 30.8407 & 0.0155 & 25.9123 \\
\hline
\end{tabular}

Applying the formula (17) to evaluate the weighted proximity index $u_{i}$, applying the formula (18) to calculate $d_{i}$. The ranking of options based on the value of $d_{i}$ were implemented. The results are as shown in Table 7.

Table 7. Several parameters in PIV

\begin{tabular}{|c|c|c|c|c|}
\hline \multirow{2}{*}{ Solutions } & \multicolumn{2}{|c|}{$u_{i}$} & \multirow{2}{*}{$d_{i}$} & \multirow{2}{*}{ Rank } \\
\cline { 2 - 4 } & $R a$ & $M R R$ & & \\
\hline$S_{I}$ & 0.0000 & 25.0234 & 25.0234 & 25 \\
\hline$S_{2}$ & 0.0016 & 25.0234 & 25.0250 & 26 \\
\hline$S_{3}$ & 0.0034 & 25.0234 & 25.0268 & 27 \\
\hline$S_{4}$ & 0.0049 & 21.4138 & 21.4186 & 19 \\
\hline$S_{5}$ & 0.0070 & 21.4138 & 21.4207 & 21 \\
\hline$S_{6}$ & 0.0093 & 21.4138 & 21.4231 & 23 \\
\hline$S_{7}$ & 0.0103 & 14.3997 & 14.4100 & 10 \\
\hline$S_{8}$ & 0.0129 & 14.3997 & 14.4126 & 11 \\
\hline$S_{9}$ & 0.0157 & 14.3997 & 14.4154 & 12 \\
\hline$S_{I 0}$ & 0.0063 & 21.4138 & 21.4201 & 20 \\
\hline$S_{I 1}$ & 0.0084 & 21.4138 & 21.4222 & 22 \\
\hline$S_{I 2}$ & 0.0107 & 21.4138 & 21.4245 & 24 \\
\hline$S_{13}$ & 0.0007 & 7.9240 & 7.9247 & 4 \\
\hline$S_{I 4}$ & 0.0023 & 7.9240 & 7.9262 & 5 \\
\hline$S_{I 5}$ & 0.0040 & 7.9240 & 7.9279 & 6 \\
\hline$S_{I 6}$ & 0.0054 & 19.4321 & 19.4375 & 16 \\
\hline$S_{I 7}$ & 0.0074 & 19.4321 & 19.4395 & 17 \\
\hline$S_{I 8}$ & 0.0096 & 19.4321 & 19.4417 & 18 \\
\hline$S_{I 9}$ & 0.0059 & 11.6991 & 11.7050 & 7 \\
\hline$S_{20}$ & 0.0083 & 11.6991 & 11.7074 & 8 \\
\hline$S_{21}$ & 0.0108 & 11.6991 & 11.7100 & 9 \\
\hline$S_{22}$ & 0.0140 & 17.9120 & 17.9260 & 13 \\
\hline$S_{23}$ & 0.0171 & 17.9120 & 17.9291 & 14 \\
\hline$S_{24}$ & 0.0203 & 17.9120 & 17.9323 & 15 \\
\hline$S_{25}$ & 0.0048 & 0.0000 & 0.0048 & 1 \\
\hline$S_{26}$ & 0.0071 & 0.0000 & 0.0071 & 2 \\
\hline$S_{27}$ & 0.0096 & 0.0000 & 0.0096 & 3 \\
\hline & & & & \\
\hline
\end{tabular}

After ranking the options according to the WASPAS and PIV methods as above, we find that two multi-criteria decision-making methods provide same results in twenty-two out of twenty-seven implemented options. Importantly, both methods indicate that the best option is the option $S_{25}$, and the worst one is the option $S_{3}$. In addition, the almost best options (rank: $2,3,4, \ldots)$ when ranked by the two methods also coincide; the almost worst options (rank: 25, 26) when ranked by the two methods also coincide. This affirms that the combination of the Entropy method with WASPAS and PIV methods has succeeded in MCDM in this study. Using the Entropy method to determine the weights for the criteria has helped the application of different $M C D M$ methods all to indicate the best solution. This was also recommended in a recent study by the authors of this study [44]. 
The differences in the ranking order of options $\left(S_{16}, S_{17}, S_{22}, S_{23}, S_{24}\right)$ have not been explained by the author of this paper at the present time. The most desired result of this study was achieved that both WASPAS and PIV methods show that for minimum surface roughness and maximum $M R R$, the values of workpiece speed, feed rate, depth of cut, dressing feed rate and dressing depth are $800 \mathrm{rev} / \mathrm{min}, 0.09 \mathrm{~mm} / \mathrm{rev}, 0.015 \mathrm{~mm}, 100 \mathrm{~mm} / \mathrm{min}$ and $0.05 \mathrm{~mm}$, respectively.

\section{CONCLUSION}

In this paper, the experimental process of cylindrical grinding 65G steel using aluminum oxide grinding wheel was presented. The Taguchi method was applied to design the experimental matrix with a total of twenty-seven experiments. Workpiece speed, feed rate, depth of cut, dressing feed rate, and dressing depth were variables in each experiment. Surface roughness and $M R R$ were selected as output parameters. The Entropy method was applied to determine the weight for each criterion. The WASPAS and PIV methods were applied for $M C D M$. Some conclusions are drawn as follows:

- With five surveyed parameters, dressing feed rate, dressing depth, workpiece speed, and feed rate has the greatest influence on the surface roughness. Meanwhile, the depth of cut has no significant influence on surface roughness.

- This is the first time that the Taguchi, Entropy, WASPAS, and PIV methods were combined to make the multi-criteria decision for grinding process. Both WASPAS and PIV method all determined same best solution.

- When making multi-criteria decisions by different methods, the Entropy method should be used to determine the weights for the criteria.

- The ranking order of options according to the WASPAS and PIV methods coincides with $22 / 27$ options, equivalent to $81.5 \%$.

- To ensure the minimum surface roughness and the maximum $M R R$ simultaneously, the value of the workpiece speed, feed rate, depth of cut, dressing feed rate and dressing depth are $800 \mathrm{rev} / \mathrm{min}, 0.09 \mathrm{~mm} / \mathrm{rev}, 0.015 \mathrm{~mm}, 100 \mathrm{~mm} / \mathrm{rev}$ and $0.005 \mathrm{~mm}$, respectively.

- In the futher work is the application of Taguchi, Entropy, WASPAS, and PIV methods to make multi-criteria decision of grinding process considering many criteria such as surface roughness, $M R R$, roundness deviation, dimensional accuracy, etc.

\section{REFERENCES}

[1] IRANI R.A., BAUER R.J., WARKENTIN A., 2005, A Review of Cutting Fluid Application in the Grinding Process, International Journal of Machine Tools \& Manufacture, 45/15, 1696-1705.

[2] VU N.P., NGUYEN Q.T., TRAN T.H., LE H.K., NGUYEN A.T., LUU A.T., NGUYEN V.T., LE X.H., 2019, Optimization of Grinding Parameters for Minimum Grinding Time When Grinding Tablet Punches by CBN Wheel on CNC Milling Machine, Applied Sciences, 9/5, 1-9.

[3] TAO Z., YAOYAO S., LAASKO S., JINMING Z., 2017, Investigation of the Effect of Grinding Parameters on Surface Quality in Grinding of TC4 Titanium Alloy, Procedia Manufacturing, 11, 2131-2138.

[4] MARINESCU I.D., HITCHINER M.P., UHLMANN E., ROWE W.B., INASAKI I., 2006, Handbook of Machining with Grinding Wheels, CRC Press. 
[5] DANESHI A., JANDAGHI N., TAWAKOLI T., 2014, Effect of Dressing on Internal Cylindrical Grinding, Procedia CIRP, 14, 37-41.

[6] KARANDE R.J., JADHAV S.M., KSHITIJ R.P., NANWATKAR R.K., 2017, Optimization of Cylindrical Grinding Machine Parameters for Minimum Surface Roughness and Maximum MRR, Global Research and Development Journal for Engineering, 2/5, 62-68.

[7] SINGH K., KUMAR P., GOYAL K., 2014, To Study the Effect of Input Parameters on Surface Roughness of Cylindrical Grinding of Heat Treated AISI 4140 Steel, American Journal of Mechanical Engineering, 2/3, 58-64.

[8] OZAY C., BALlIKAYA H., SAVAS V., 2016, Application of the Taguchi Method to Select the Optimum Cutting Parameters for Tangential Cylindrical Grinding of AISI D3 Steel, Materials and Technology, 50/1, 81-87.

[9] SINGH T., GOYAL K., KUMAR P., 2014, To Study the Effect of Process Parameters for Minimum Surface Roughness of Cylindrical Grinded AISI 1045 Steel, Manufacturing Science and Technology, 2/3, 56-61.

[10] TU H.X., THAO L.P., HONG T.T, NGA N.T.T., TRUNG D.D., GONG J., PI V.V., 2018, Influence of Dressing Parameters on Surface Roughness of Workpiece for Grinding Hardened 9XC Tool Steel, IOP Conf. Series: Materials Science and Engineering, 542, 1-7.

[11] MOHITE D.D., NEERAJ T., SANDEEP S., UDAYHANKAR M., 2017, Modelling and Optimization of Dressing Parameters of CNC Cylindrical Grinding Wheel for Minimum Surface Roughness, International Journal of Engineering Research and General Science, 5/4, 102-111.

[12] PATEL D.K., GOYAL D., PABLA B.S., 2018, Optimization of Parameters in Cylindrical and Surface Grinding for Improved Surface Fnish, Royal Society Open Science, 5/5, 1-11.

[13] PRASAS S.D., VISHAL S., VISHAL S., BHARGAV K., ROGITH K., 2021, Cylindrical Grinding - Experimental Investigation and Taguchi Study of Process Parameters on EN31 and Mild Steel, IOP Conf. Series: Materials Science and Engineering, 1057, 1-15.

[14] MEKALA K., CHANDRADAS J., CHANDRASEKARAN K., KANNA T.T.M., RAMESH E., BABU R.N., 2014, Optimization of Cylindrical Grinding Parameters of Austenitic Stainless Steel Rods (AISI 316) by Taguchi Method, International Journal of Mechanical Engineering and Robotics Research, 3/2, 208-215.

[15] HUNG L.X., HONG T.T., KY L.H., TUNG L.A, NGA N.T.T., PI N.V., 2018, Optimum Dressing Parameters for Maximum Material Removal Rate When Internal Cylindrical Grinding Using Taguchi method, International Journal of Mechanical Engineering and Technology, 9/12, 123-129.

[16] TRUNG D.D., THIEN N.V., NGUYEN N.T., 2021, Application of TOPSIS Method in Multi-Objective Optimization of the Grinding Process Using Segmented Grinding Wheel, Tribology in Industry, 43/1, 12-22.

[17] REKAH R., BASKAR N., PADMANABAN M.R.A, PALANISAMY A., 2020, Optimization of Cylindrical Grinding Process Parameters Using Meta-Heuristic Algorithms, Indian Journal of Engineering \& Materials Sciences, 27, 389-395.

[18] HUNG L.X., PI N.V., HONG T.T., KY L.H., LIEN V.T. TUNG L.A., LONG B.T., 2018, Multi-Objective Optimization of Dressing Parameters of Internal Cylindrical Grinding for 9CrSi Aloy Steel Using Taguchi Method and Grey Relational Analysis, Materials Today: Proceedings, 18, 2257-2264.

[19] RUDRAPATI R., BANDYOPADHYAY A., KUMAR P., 2018, Parametric Optimization of Cylindrical Grinding Process through Hybrid Taguchi Method and RSM Approach using Genetic Algorithm, Iranian Journal of Mechanical Engineering, 19/1, 34-62.

[20] WANG C.L., LAI Y.J., LIU T.Y., 1993, A New Approach for Multiple Objective Decision Making, Computers \& Operations Research, 20/8, 889-899.

[21] OPRICOVIC S., TZENG G.H., 2004, Compromise Solution by MCDM Methods: A Comparative Analysis of VIKOR and TOPSIS, European Journal of Operational Research, 156/2, 445-455.

[22] BRAUERS W., 2004, Optimization Methods for a Stakeholder Society. A Revolution in Economic Thinking by Multi-Objective Optimization, Kluwer Academic Publishers.

[23] TRIANTAPHYLlOU E., 2020, Multi-Criteria Decision Making Methods: A Comparative Study, Springer Science + Busines Media, Springer US.

[24] PEREZ E.C, LAMATA M.T., VERDEGAY J.L., 2016, RIM-Reference Ideal Method in Multicriteria Decision Making, Information Sciences, 337/10, 1-10.

[25] ZAVASDSKAS E.K., TURSKIS Z., ANTUCHEVICIENE J., ZAKAREVICIUS A., 2012, Optimization of Weighted Aggregated Sum Product Assessment, Electronics and Electrical Engineering, 122/6, 3-6.

[26] MUFAZZAL S., MUZAKKIR S.M., 2018, A New Multi-Criterion Decision Making (MCDM) Method Based on Proximity Indexed Value for Minimizing Rank Reversals, Computers \& Industrial Engineering, 119, 427-438.

[27] KHAN N.Z., ANSARI T.S.A., SIDDIQUEE A.N., KHAN Z.A., 2019, Selection of E-Learning Websites Using a Novel Proximity Indexed Value (PIV) MCDM Method, Journal of Computers in Education, 6, 241-256.

[28] WAKEEL S., BINGOL S., BASHIR M.N., AHMAD S., 2021, Selection of Sustainable Material for the Manufacturing of Complex Automotive Products Using a New Hybrid Goal Programming Model for Best Worst Method- 
Proximity Indexed Value Method, Proceedings of the Institution of Mechanical Engineers, Part L: Journal of Materials: Design and Applications, 235/2, 1-15.

[29] ULUTAS A., KARRAKOY C., 2019, An Analysis of the Logistics Performance Index of EU Countries with an Integrated MCDM Model, Economics and Business Review, 5/4, 49-69.

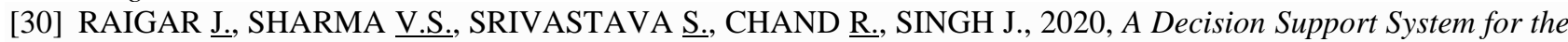
Selection of an Additive Manufacturing Process Using a New Hybrid MCDM Technique, Sadhana, 45/101, 1-14.

[31] JAYANT R., SINGH S., GARG S.K., 2018, An Integrated Approach with MOORA, SWARA, and WASPAS Methods for Selection of $3 P L S P$, Proceedings of the International Conference on Industrial Engineering and Operations Management, 2497-2509.

[32] DARJAN K., DRAGISA S., SNEZANA U., MAKSIMVIC M., 2016, An Approach to Personnel Selection Based on SWARA and WASPAS Methods, Journal of Economics, Management and Informatics, 7/1, 1-11.

[33] YAZDANI M., ZAVADSKAS E. K., IGNATIUS J., ABAD M.D., 2016, Sensitivity Analysis in MADM Methods: Application of Material Selection, Inzinerine Ekonomika-Engineering Economics, 27/4, 382-391.

[34] ONAJITE O., OKE S.A., 2021, The Application of WSM, WPM and WASPAS Multicriteria Methods for Optimum Operating Conditions Selection in Machining Operations, Urnal Rekayasa Sistem Industri, 10/1, 1-14.

[35] VYGANTAS B., KAZIMIERAS E.Z., ZENONAS T., 2013, Multi-Criteria Selection of a Deep-Water Port in Klaipeda, Procedia Engineering, 57, 144-148.

[36] LIU J.D., WANG G.C., WANG B.L., CHEN K.M., 2007, Study on the Formation of Grind-Hardening of Steel AISI 1066, Key Engineering Materials, 329, 57-62.

[37] LIU J., XIONG J., YUAN W., 2012, Experiment Study on Grinding Force of 65Mn Steel in Grinding-Hardening Machining, Lecture Notes in Electrical Engineering, 173, 239-246.

[38] TRUNG D.D., 2021, Influence of Cutting Parameters on Surface Roughness in Grinding of 65G Steel, Tribology in Industry, 43/1, 167-176.

[39] HIEU T.T., THAO N.X., THUY L.T.M., 2019, Application of MOORA and COPRAS Models to Select Materials for Mushroom Cultivation, Vietnam Journal of Agricultural Sciences, 17/4, 32-2331.

[40] DEAN A., VOSS D., DRAGULJIC D., 2007, Design and Analysis of Experiments - Second Edition, Springer.

[41] MALKIN S., GUO C., 2008, Grinding technology: Theory and Applications of Machining with Abrasives, New York: Industrial Press.

[42] TIEN D.H., TRUNG D.D., THIEN N.V. NGUYEN N.T, 2021, Multi-Objective Optimization of the Cylindrical Grinding of SCM440 Steel Using Reference Selection Index Method, Journal of Machine Engin., 21/3, 110-123.

[43] MALKIN S., ANDERSON R.B., 1974, Thermal Aspects of Grinding, Part 1 - Energy Partition, Journal of Manufacturing Science and Engineering 96/4, 1177-1183.

[44] TRUNG D.D., 2021, A Combination Method for Multi-Criteria Decision Making Problem in Turning Process, Manufacturing Review, 8/26, 1-17. 